\title{
As mulheres católicas e as origens do Serviço Social: o caso do Instituto Social do Rio de Janeiro (1937-1947)*
}

Catholic women and the origins of social work: the case of the Rio de Janeiro's Instituto Social (1937-1947)

Ana Paula Vosne Martins*

Resumo - O artigo trata das origens religiosas e conservadoras do Serviço Social e da agência das mulheres católicas na organização da ação social e das escolas de educação familiar e doméstica. A primeira parte do artigo aborda as relações entre o catolicismo e o engajamento feminino na ação social. Na segunda parte o foco se volta para as religiosas da Sociedade das Filhas do Coração de Maria e para Stella de Faro, liderança da Ação Católica Brasileira, na criação da primeira escola católica de Serviço Social do Rio de Janeiro, o Instituto Social.

Palavras-chave: catolicismo; conservadorismo; mulheres; ação social; Serviço Social

\begin{abstract}
The article discusses the conservative and religious origins of social work and the agency of Catholic women in the organization of social action and schools of domestic and family education. The first part of the article discusses the relations between Catholicism and feminine engagement in social action. In the second part, the focus switches to religious women of the Society of the Daughters of the Heart of Mary and Stella de Faro, leader of the Ação Católica Brasileira (Brazilian Catholic Action), in the creation of Rio de Janeiro's first Catholic school of social work, Instituto Social.

Keywords: Catholicism; conservatism; women; social action; social work.
\end{abstract}

\footnotetext{
* Este artigo é resultado de pesquisa financiada pelo CNPq como bolsista de produtividade.

** Doutora em História pela Unicamp, com pós-doutorado na Casa de Oswaldo Cruz/FIOCRUZ e na Universidade Federal Fluminense. É professora do Departamento de História e do Programa de Pós-Graduação em História na Universidade Federal do Paraná e pesquisadora do Núcleo de Estudos de Gênero nesta universidade. É bolsista de Produtividade do Conselho Nacional de Desenvolvimento Científico e Tecnológico (CNPq).E-mail: ana_martins@ uol.com.br. ORCID:https://orcid.org/0000-0002-1715-1599.
} 


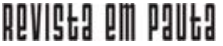

\} AS MULHERES CATÓLICAS E AS ORIGENS - MARTINS, A. P. V.

DOI: $10.12957 /$ rep.2021.56088

Em 1937 foi fundado na cidade do Rio de Janeiro o Instituto de Educação Familiar e Social, segunda escola católica de formação de assistentes sociais e educadoras familiares no Brasil. Há referências sobre as primeiras escolas católicas em publicações de pesquisadoras do Serviço Social, geralmente a respeito da história da organização do ensino e de suas diretrizes doutrinais, teóricas e metodológicas, bem como algumas informações mais pontuais a respeito dos promotores daquelas iniciativas (LIMA, 1983; BACKX, 1993; MESTRINER, 2005; MACHADO, 2015).

Compreende-se que a abordagem destes e de outros trabalhos seja no sentido de explicar o contexto histórico da criação das escolas e da organização do ensino do Serviço Social, razão pela qual não tiveram como objetivo produzir uma análise histórica mais específica que articulasse o nível político-ideológico com as trajetórias e as inter-relações dos diferentes atores envolvidos com as origens do Serviço Social no Brasil. Mesmo um trabalho mais específico e de alta qualidade sobre o Instituto Social, como a dissertação de mestrado de Sheila S. Backx (1993), não se deteve nos atores, mas sim nas orientações doutrinais e teóricas transmitidas pela escola, ao analisar os trabalhos de conclusão de curso entre as décadas de 1940 e 1950.

Este artigo apresenta uma proposta de análise que vai em outra direção. Propõe uma análise histórica das origens do Serviço Social que privilegia duas dimensões pouco ou escassamente presentes não só nos estudos da área, mas igualmente na história das mulheres: a religião e a agência feminina conservadora.

Os estudos sobre a história das mulheres e a religião foram marcados pelo enfoque na suspeição e no controle do corpo feminino e da sexualidade, ou então pela discussão sobre as formas de opressão e subordinação feminina por parte de uma instituição hierárquica e masculina como a Igreja Católica (BROWN,1990; FOUILLOUX, 1995; RANKE-HEINEMANN, 1996). Mais recentemente as abordagens históricas têm privilegiado a agência religiosa feminina, entendida como a capacidade de ação, escolhas, projetos, adequação e margens de criação por parte das mulheres, mesmo em situações de subordinação e de dominação, afinal estas situações nem sempre são restritivas ou impeditivas de protagonismo e de fortalecimento das mulheres em suas comunidades religiosas(SARTI, 1984; FAYET-SCRIBE, 1990 ; KANE, 1991; GIORGIO, 1994; FOUILLOUX, 1995; COVA, 2000; CLARK, 2004; MAHMOOD, 2005; DELLA SUDDA, 2007; COVA; DUMONS, 2010; DAWES, 2011).

Permanecendo no campo religioso católico, tendo em vista a contribuição historiográfica internacional significativa sobre as mulheres protestantes, nota-se uma constante na historiografia feminista que é o pouco interesse não só pelas mulheres conservadoras, mas por suas alianças devocionais e políticas com a Igreja Católica. A análise proposta neste artigo se alinha às reflexões desenvolvidas por pesquisadoras como Della Sudda 
(2007), para as católicas, e Mahmood (2005), para as muçulmanas, a respeito da agência feminina conservadora ou, mais adequadamente, dos paradoxos do conservadorismo feminino, seja pela militância religiosa e política, seja pela afirmação de um lugar de ação para as mulheres sem subversão das hierarquias e das relações de poder. Procura-se entender as margens de ação de mulheres católicas - laicas e religiosas -, reveladoras de seu alinhamento inconteste com a doutrina e as orientações da Igreja a respeito do papel que os católicos - homens e mulheres - deveriam desempenhar no mundo, no sentido de recuperar seu poder, e a unidade de sua direção espiritual e temporal.

Para tanto o foco da análise se ajusta para a agência feminina num terreno fundamental para o catolicismo desde meados do século XIX, que foi a delimitação da "questão social" e de seus inúmeros "remédios", entre eles a educação e a intervenção social no sentido de correção e de ajuste do que então se denominava "males sociais", advindos das profundas transformações econômicas e sociais do capitalismo industrial e que afetaram de forma mais contundente as famílias das classes trabalhadoras. A partir das diretrizes formuladas pela teoria do catolicismo social ao longo do século XIX e sistematizadas pela encíclica Rerum Novarum, de Leão XIII, em 1891, foram organizadas diversas associações e iniciativas de educação e intervenção social, sendo o Serviço Social uma delas, tanto como conhecimento dos problemas sociais, e também como profissão a ser exercida ideal e preferencialmente por mulheres.

A partir da criação de escolas católicas de Serviço Social, como foi o Instituto de Educação Familiar e Social do Rio de Janeiro, a primeira parte do artigo tem como objeto de análise a organização dessas escolas no cenário europeu à luz dos valores e princípios norteadores do catolicismo social, bem como a atuação feminina laica e religiosa. Na segunda parte a análise se direciona para o papel desempenhado pela congregação feminina Sociedade das Filhas do Coração de Maria, tanto na mobilização da militância católica internacional, como também na educação social, com destaque para o protagonismo da primeira Filha do Coração de Maria do Brasil, a liderança feminina da Ação Católica Brasileira, Stella de Faro (18881972), não apenas idealizadora, mas também uma das fundadoras e diretora do Instituto Social do Rio de Janeiro, como passou a ser denominado a partir de 1939.

\section{A ação social feminina}

Entre 1898 e 1899 o intelectual católico francês Max Turmann (1866-1943) ministrou conferências no Collège Libre des Sciences Sociales, em Paris, onde era professor de Ciências Políticas e Econômicas. Definido por Lanfrey (1987) como um democrata cristão, Turmann representa bem 


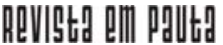

\} AS MULHERES CATÓLICAS E AS ORIGENS - MARTINS, A. P. V. \}

DOI: $10.12957 /$ rep.2021.56088

o católico militante que já se apresenta no século XIX como um combatente da causa da Igreja e da fé católica no mundo, desempenhando seu papel intelectual como divulgador da doutrina e principalmente dos princípios norteadores do catolicismo social. Suas publicações demonstram como se tornou um especialista nas questões sociais, abrangendo temas como sindicalismo, direitos dos operários, associativismo agrícola, patronatos para a juventude, educação popular e ação social das mulheres católicas.

Naquelas conferências, que depois foram publicadas em livro (TURMANN, 1900), explicava que o catolicismo social era uma doutrina sustentada no Evangelho para enfrentar os problemas decorrentes das transformações sociais e econômicas do mundo moderno e também uma resposta ao coletivismo revolucionário e à organização dos sindicatos socialistas. $\mathrm{O}$ interesse da Igreja pelas múltiplas facetas da questão social demonstrava, segundo Turmann, como esta não se encontrava isolada, muito menos distante da realidade do mundo. Sob a orientação das encíclicas papais e dos bispos, os católicos de diferentes países se empenhavam em conhecer e estudar os problemas sociais mais urgentes, propor soluções e se dedicar à sua execução, tanto por meio de iniciativas mais antigas, como obras de caridade, quanto pela criação de novas instituições que respondessem às urgências do tempo, entre elas a educação de crianças e jovens, o apoio às famílias dos trabalhadores e a orientação cristã na organização sindical dos trabalhadores.

Nesse livro ele traça as origens históricas do catolicismo social, remontando à década 1840 na Alemanha e às décadas de 1860 e 1870 na França. O envolvimento de clérigos e de laicos na defesa dos direitos dos trabalhadores fez parte não só da aproximação dos católicos com o mundo do trabalho, mas igualmente do envolvimento com a política e a proposição de leis protetoras dos trabalhadores. Ao mesmo tempo esse movimento social dos católicos resultou num amplo conjunto de estudos produzidos especialmente por laicos, como o próprio Turmann, sobre os problemas sociais, o que deu origem ao pensamento social católico que, segundo o autor, desaguou na Rerum Novarum.

Inicialmente o movimento foi orientado mais para a organização dos trabalhadores, ou do sindicalismo cristão, em oposição ao sindicalismo socialista, como atestam várias publicações e organizações, entre elas a Ação Popular, na Bélgica e na França, cujas atividades foram iniciadas em 1903 sob a orientação dos jesuítas (DROULERS,1981). O movimento católico estava representado também nos parlamentos da Holanda, Alemanha, Áustria, França, Suíça, Bélgica, além de oradores bem preparados e pessoas envolvidas em obras sociais católicas em vários lugares do mundo. Turmann se refere também à imprensa católica como importante instrumento de divulgação das ideias sobre o movimento social, trazendo uma longa lista de revistas e jornais católicos por país (TURMANN, 1900, p. 19-20). 


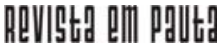

\} AS MULHERES CATÓLICAS E AS ORIGENS - MARTINS, A. P. V.

DOI: $10.12957 /$ rep.2021.56088

Mas o catolicismo social são se restringiu à organização dos trabaIhadores. Outros dois campos importantes foram a educação popular, com destaque para as crianças e os adolescentes, e a família dos trabalhadores por meio da orientação e da educação das mulheres no seu papel de esposas e mães. Assim, observa-se que a frente da ação social não era homogênea: num sentido mais político a ação social era masculina, praticada por homens de elite para homens das classes populares e para a própria organização dos laicos; mas se esperava que as mulheres católicas também participassem da ação social, que elas irrigassem esse vasto campo com a sua larga experiência nas obras de caridade e com sua notória benevolência celebrizada pelas vidas de santas, mas igualmente pela ação de muitas mulheres de elite que patrocinaram obras voltadas para o atendimento aos pobres, aos doentes e às crianças (MARTINS, 2013).

A participação das mulheres na vida religiosa foi intensa e crescente ao longo de todo o século XIX, sendo um forte apoio ao movimento restaurador da Igreja Católica, tanto pelas práticas devocionais, quanto pela histórica adesão às obras de caridade. No entanto, o clero e os laicos envolvidos com a ação social reconheceram que para além da piedade as mulheres tinham um conhecimento social prático, bem como uma capacidade organizativa que não poderiam ser negligenciados pelo movimento de reconquista social e religiosa do catolicismo. Foi este reconhecimento que motivou homens como Max Turmann e tantos outros intelectuais do fim do século XIX a incentivar as mulheres a se engajarem na ação social católica. Não é coincidência que um dos primeiros livros de Turmann publicados no início do século XX tivesse como título Iniciativas Femininas, no qual ele reconhece a importância das obras sociais femininas e estimula o envolvimento das mulheres de elite na organização e na educação das mulheres das classes trabalhadoras, como suas mestras e orientadoras. Surgia, portanto, no fim do século XIX, a ação social feminina católica (TURMANN, 1905).

Essa participação feminina era bastante abrangente e variava de país para país, dependendo das necessidades que se apresentavam como mais urgentes. Retomando o citado livro de Turmann, de 1905, a atuação do movimento feminino católico em diferentes países se dava em obras para a educação de crianças e de jovens moças trabalhadoras, educação religiosa nas paróquias, educação popular em comunidades rurais, educação doméstica para as mulheres pobres e donas de casa, obras de assistência e proteção às mães e às crianças pobres, criação de jardins de infância, colônias de férias para filhos de trabalhadores e proteção à moça trabalhadora, com o fornecimento de apoio moral, material, espiritual e de prevenção à prostituição. ${ }^{1}$

\footnotetext{
1 Em 1896 foi criada em Friburgo, na Suíça, a Obra católica de proteção à moça por Susanne de Montenach e Louise de Reynold, representantes da aristocracia católica. Buscava dar amparo material e espiritual às jovens suiças trabalhadoras, mesmo as que emigraram em busca de trabalho. Tornou-se a Associação Internacional Católica de Proteção à Moça, apoiada pelo episcopado suíço e da Santa Sé (MEUWLY-GALLEY, 1998).
} 


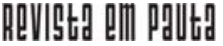

\} AS MULHERES CATÓLICAS E AS ORIGENS - MARTINS, A. P. V. \}

DOI: $10.12957 /$ rep.2021.56088

A ação social feminina se concentrava em duas importantes frentes: a educação e a assistência social, sendo que em algumas obras as duas frentes eram indissociáveis, como a educação social e doméstica para as mulheres pobres. Desde as últimas três décadas do século XIX começaram a ser criadas escolas domésticas em diferentes países europeus visando à educação das mulheres trabalhadoras com o objetivo de que permanecessem em seus lares a desempenhar com conhecimento seu papel de esposa e de mãe (ROLL, 2009). Mulheres da aristocracia e da burguesia urbana e rural se engajaram nessa ação educativa formando escolas e escrevendo sobre o assunto, como demonstraram Eliane Gubin (2002) e Sandrine Roll (2009). Cabe destacar que escolas desse tipo foram espaços de formação para mulheres das classes trabalhadoras, mas também para as mulheres da burguesia, como foi o caso da Escola Normal Social, fundada em 1911, em Paris, por uma aristocrata, Madame Butillard. Foi uma escola de formação para mulheres de elite que desejavam ter acesso aos mais recentes conhecimentos sobre a economia doméstica e os problemas sociais, bem como foi uma escola para formar as "propagandistas", como eram chamadas as jovens mulheres das classes populares que deveriam inculcar os conhecimentos técnicos e a espiritualidade cristã adquiridos na escola social nos meios populares onde viviam, conforme a parábola de Jesus sobre o fermento presente em Mateus13:33 e Lucas 13:21. Depois de 1920 a Escola Normal Social passou a ser um centro de formação de assistentes sociais (PIERRARD, 1988).

Também em Paris foi criado em 1916 o Instituto Social, Familiar e de Economia Doméstica, uma escola idealizada pelo Arcebispo de Paris, Leon Adolphe Amette, que solicitou à congregação da Sociedade das Filhas do Coração de Maria que dirigisse a escola. ${ }^{2}$ Na Bélgica foi criada em 1920 a Escola Católica Feminina de Bruxelas, nos mesmos moldes das escolas francesas, dirigida pelas lideranças laicas católicas Victoire Campe e Maria Baers. Também voltada para a formação doméstica, a Escola Normal Social, que contava com o apoio irrestrito do Cardeal Mercier, Arcebispo de Bruxelas, tornou-se uma das escolas de Serviço Social mais importantes da Bélgica (ZELIS, 2001).

Esta cronologia da educação doméstica e social na França e na Bélgica é importante para compreender uma experiência que serviu de modelo na atuação das mulheres católicas brasileiras no processo de criação das escolas de Serviço Social no Brasil, em particular o Instituto Social do Rio de Janeiro. É importante lembrar que houve uma forte orientação laica nas origens da educação e da profissão do Serviço Social nos Estados Unidos e em outros países europeus, que teve influência nas escolas de serviço social brasileiras, influência mais conhecida pela bibliografia especializada, mas neste artigo o enfoque é sobre as origens religiosas da profissão (WAL-

${ }^{2}$ Informações disponíveis em: www.cloriviere.paris/isc/. Acesso em: 10 fev. 2019. 
KOWITZ, 1990). Assim, cabe ainda entender a relação entre a ação social e a militância católica feminina. Tendo em vista a extensão desse tema, o destaque será na atuação das religiosas da Sociedade das Filhas do Coração de Maria, que tiveram um papel fundamental na criação do Instituto Social, praticamente desconhecido pela bibliografia sobre o Serviço Social e sobre a história das mulheres.

Essa congregação foi criada no fim do século XVIII pelo padre jesuíta Pierre-Joseph de Clorivière (1735-1820) com a participação devota da aristocrata Adélaïde-Marie Champion de Cicé (1749-1818) com a finalidade de preservar a vida religiosa consagrada no contexto da Revolução Francesa. Essa congregação foi criada para que as religiosas pudessem atuar no mundo sem encontrar obstáculos e perseguições; assim, no Estatuto de 1828 se encontram bem definidas as suas regras: não haver nenhum sinal exterior que distinga as religiosas das mulheres laicas, ou seja, não usariam hábito religioso; não era necessário mudar seu gênero de vida e nem deixar sua família, portanto não viveriam numa casa religiosa ou convento. Podiam ser de qualquer origem social, contanto que fosse compatível com a prática dos conselhos evangélicos, das regras e dos deveres da Sociedade. No mais deviam fazer os votos de castidade, de obediência e de pobreza, sendo que a respeito deste cada uma poderia conservar o que recebesse de suas famílias, mas não poderia aumentar sua riqueza ou herança por apego excessivo às coisas materiais (ESTATUTO, 1828).

Ao longo do século XIX elas se dedicaram à educação de meninas e se mantiveram sob a direção espiritual dos jesuítas, mas a partir do fim do século passaram a ter um novo e destacado papel na ação social católica, particularmente na organização do movimento feminino católico internacional. Por ser uma congregação presente em vários países, com quadros formados por uma sólida educação religiosa e intelectual, mas também por estarem protegidas das investidas políticas anticlericais em países republicanos e liberais, afinal não portavam nenhum sinal exterior de que eram religiosas, as Filhas do Coração de Maria tinham uma capacidade de mobilização e de inserção nos movimentos católicos laicos que outras congregações que atuavam no mundo social não tinham. A partir do começo do século XX as Filhas do Coração de Maria se engajaram fortemente na ação social e na organização do movimento católico feminino, participando da criação de importantes organizações de massa na França e na Itália e na criação da primeira organização internacional de mulheres católicas, a Federação Internacional das Ligas Católicas Femininas, em 1910, e posteriormente na Ação Católica (DELLA SUDDA, 2007).

Uma destacada Filha do Coração de Maria esteve no Brasil em 1932 a convite do Arcebispo do Rio de Janeiro, Dom Sebastião Leme, para ministrar um curso preparatório da Ação Católica para as mulheres que atuavam nas organizações, tendo em vista que Dom Leme vinha imprimindo uma direção firme de organização do laicato desde o começo da década 


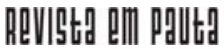

\} AS MULHERES CATÓLICAS E AS ORIGENS - MARTINS, A. P. V. \}

DOI: $10.12957 /$ rep.2021.56088

de 1920, com a criação da Confederação Católica, um experimento do que viria a ser a Ação Católica Brasileira, criada em 1935 pelo então Cardeal Leme. ${ }^{3}$ Christine de Hemptinne (1895-1984) nasceu em uma família da nobreza belga e teve uma educação privada de alta qualidade. Muito católica, desde jovem se dedicava às obras de caridade em sua cidade natal, Gand, atuando como enfermeira no atendimento aos soldados feridos durante a Primeira Guerra Mundial num hospital improvisado na propriedade da família. Em 1918 ela entrou para a Sociedade das Filhas do Coração de Maria e se envolveu intensamente com a ação social nos bairros operários de Gand e com a educação religiosa de crianças e adolescentes. Em 1924 o Cardeal Mercier, de Bruxelas, encarregou-a da Ação Católica da Juventude Feminina Belga, a primeira organização da Ação Católica naquele país, participando como representante das Mulheres Católicas Belgas na União Internacional das Ligas Católicas Femininas, nome que passou a ter a organização criada em 1910, a Federação Internacional das Ligas Católicas Femininas (GUBIN et al., 2006). A partir da década de 1920 Christinne passou a ser um nome reconhecido internacionalmente na organização da juventude feminina católica e este foi o motivo pelo qual veio ao Brasil. Cabe destacar que foi a partir deste curso ministrado por Hemptinne que Dom Leme decidiu criar no Brasil a primeira organização da Ação Católica, a Juventude Feminina Católica, seguindo a mesma decisão de Mercier na Bélgica.

Naquele mesmo ano de 1932 a importante liderança feminina católica brasileira, Stella de Faro, viajava a Paris para participar do congresso da União Internacional das Ligas Católicas Femininas e iniciava seu noviciado na Sociedade das Filhas do Coração de Maria, fazendo seus votos alguns anos depois no Brasil, quando a congregação se instalou no Rio de Janeiro, sendo Stella de Faro a primeira Filha do Coração de Maria do Brasil. ${ }^{4}$ A partir dessa decisão que começara a amadurecer desde 1925, segundo informações biográficas, e do comprometimento de Dom Leme com a ação social católica, é que se cruzaram os caminhos da congregação, da militância católica feminina e do Instituto Social do Rio de Janeiro.

\section{Uma escola feminina de educação social e familiar}

Stella de Faro foi uma militante católica de primeira linha. Oriunda de uma família da nobreza imperial e muito católica, há registros de sua devoção e participação em organizações religiosas desde muito jovem,

\footnotetext{
${ }^{3}$ Vieram duas religiosas, Christinne de Hemptinne e Jeanne Putzeys, com a intenção de também sondar se haveria candidatas brasileiras para ingressar na congregação. Acervo do Instituto Social de Curitiba, Biografia de Stella de Faro, documento datilografado, s.d.

${ }^{4}$ Seus votos foram realizados em 1938 na presença de três Filhas do Coração de Maria que se encontravam no Brasil e dos padres jesuítas Marcelo Renaud e Leonel Franca, na capela da Congregação, numa residência em Botafogo. Acervo do Instituto Social de Curitiba, Biografia de Stella de Faro, documento datilografado, s.d.
} 


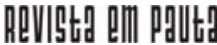

\} AS MULHERES CATÓLICAS E AS ORIGENS - MARTINS, A. P. V. \}

DOI: $10.12957 /$ rep.2021.56088

tendo ingressado na Pia União das Filhas de Maria quando passou a frequentar o Colégio de Sion em Petrópolis a partir de 1904. Na imprensa carioca também há vários registros de sua militância, tanto na imprensa laica, quanto na imprensa católica, para a qual colaborou intensamente em jornais como A Cruz e A União, além de ter sido editora por muitos anos da Revista do Apostolado das Filhas de Maria desde 1912. Formada pela orientação doutrinal da restauração católica ultramontana, os escritos de Stella revelam sua adesão incondicional à ação católica, demonstrada pelas muitas organizações das quais participou sempre como líder, tendo sido uma pessoa da confiança de Dom Sebastião Leme. Ele a convidou para organizar e dirigir a Associação das Senhoras Brasileiras, criada em 1920, uma organização católica de formação, proteção e apoio às jovens trabalhadoras, mas principalmente para liderar a seção feminina da Ação Católica Brasileira, ao lado de seu amigo Alceu Amoroso Lima, responsável pela seção masculina (MESQUIDA, 2009; MARTINS, 2016).

Sua origem social de elite e a inserção nos meios católicos devocionais e intelectuais do Rio de Janeiro criaram as condições propícias para Stella colocar em prática muitas de suas ideias a respeito das mulheres. Ela sempre adotou um discurso conservador e bem alinhado às orientações clericais a respeito do lugar social das mulheres, a saber, a família e a maternidade. Contudo, um dos paradoxos do conservadorismo católico à época é que ao mesmo tempo em que reforçava as hierarquias de gênero, dava oportunidade para algumas mulheres, como Stella e suas colegas belgas e francesas, de atuar no mundo, de exercer atividades públicas e manifestar suas ideias por meio da palavra falada e escrita, terrenos quase exclusivamente masculinos e que foram ocupados por muitas mulheres católicas naquele tempo.

Para Stella as mulheres deveriam seguir rigorosamente as orientações religiosas cristãs, obedecer e se submeter à autoridade clerical e principalmente agir de acordo com a moralidade católica de forma a ter uma conduta exemplar na família, na Igreja e na sociedade. Apesar desse discurso tão conformista e obediente à ordem e à autoridade masculinas, para Stella os limites das mulheres não estavam restritos à família e às práticas devocionais exclusivamente, embora as valorizasse muito como manifestações da correção e adequação femininas. Seguindo uma orientação corrente no pensamento e nas publicações católicas que ela conhecia bem, a ação das mulheres deveria ir além dos seus lares, das igrejas e das associações de piedade e caridade. Elas deveriam ser o fermento, o sal, a força mobilizadora e animadora do élan cristão e compor a frente de batalha na defesa da fé e da Igreja Católica, de acordo com os discursos militantes da época.

Tal expectativa não era pouco para as boas mulheres católicas e exigia preparação. Stella procurou ao longo de sua vida atender a este chamado à causa de uma forma bastante discreta e modesta, como se esperava 


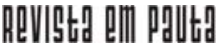

\} AS MULHERES CATÓLICAS E AS ORIGENS - MARTINS, A. P. V. \}

DOI: $10.12957 /$ rep.2021.56088

de uma Filha do Coração de Maria. Talvez esteja aí a resposta para as poucas e fragmentadas informações a respeito da vida de Stella de Faro, inclusive as raras fotografias que dela permaneceram, nas quais é possível notar sua disposição corporal contida, esboço de sorriso, olhar sereno e roupas muito discretas. É importante lembrar que Stella queria entrar para a vida religiosa desde os tempos de juventude no Colégio de Sion, mas por motivos familiares adiou esta decisão. No entanto, a obediência, a modéstia e a piedade de Stella de Faro não foram impedimentos para a sua ação no mundo e a capacidade que demonstrou de tecer relações de amizade, de confiança e de respeito, obtendo visibilidade para todas as causas às quais se dedicou, entre elas a educação das jovens mulheres.

Ainda muito jovem Stella participou do Segundo Congresso Católico Brasileiro, no Rio de Janeiro, em 1908, e como uma boa militante apresentou a tese intitulada Escolas Populares de Economia Doméstica, que foi aprovada pelos organizadores (FARO, 1908). Stella já conhecia as iniciativas europeias para a educação popular e feminina, a educação doméstica. Para ela a economia doméstica era uma ciência que envolvia todos os elementos da vida cotidiana, importante para todas as mulheres, independentemente de sua classe social, mas em especial para as mulheres do povo. A tese permaneceu no papel, mas, com a criação da Associação das Senhoras Brasileiras (ASB), ela começou a colocar em prática suas ideias de educação feminina popular.

A ASB oferecia cursos para as moças de famílias mais pobres e que precisavam trabalhar, especialmente as comerciárias que trabalhavam no centro da cidade do Rio de Janeiro. Além dos cursos, a ASB fornecia refeições a preços módicos e tinha uma agência de empregos para apoiar as jovens trabalhadoras. A Escola Comercial da ASB tinha no seu corpo docente homens e mulheres dos quadros da militância católica e oferecia cursos diurnos e noturnos de Línguas, Ciências, Letras, Datilografia, Taquigrafia e Escrituração Mercantil, além dos cursos de Costura, Chapéus, Higiene e Puericultura. A imprensa carioca deu muito espaço para divulgar os cursos e as atividades da ASB, com destaque para sua diretora Stella de Faro. Interessante notar que a educação cristã nos limites do que então se considerava adequado às jovens moças das classes populares as preparava para conquistar postos de trabalho mais qualificados e que pagavam salários melhores, como informava a imprensa.

O conhecimento que tinha sobre as escolas de educação social e doméstica na Europa e a prática adquirida à frente da ASB se somou à experiência pessoal, pois Stella frequentou cursos no Instituto Familiar, Social e de Educação Doméstica e no Instituto Católico, em Paris, por ocasião de sua viagem em 1932. Como comentado na primeira parte deste artigo, esse Instituto parisiense estava sob a direção das Filhas do Coração de Maria, congregação para a qual Stella ingressou no noviciado, sob a orientação de Fanny du Rostu, irmã de Marie du Rostu, outra liderança do movimento 


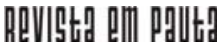

\} AS MULHERES CATÓLICAS E AS ORIGENS - MARTINS, A. P. V.

DOI: $10.12957 /$ rep.2021.56088

católico feminino francês e internacional e também Filha do Coração de Maria, sendo uma referência religiosa e intelectual da Ação Católica feminina.

A frequência aos cursos do Instituto Familiar, Social e de Educação Doméstica parisiense fortaleceu em Stella a convicção de que havia um tipo de educação feminina que se adequava bem aos propósitos da ação social católica, tanto do ponto de vista individual de formação moral, religiosa e prática, quanto do ponto de vista mais amplo da preparação profissional e técnica para a intervenção católica na sociedade, em especial nos chamados "problemas sociais". Stella já conhecia bem as experiências europeias de educação social e doméstica, como a organização do Serviço Social, além de ter estabelecido relações próximas com Christine de Hemptinne e com uma importante professora católica belga, Adèle Lhoneaux, que também esteve no Brasil em 1932 para realizar um curso de ação social em São Paulo e ministrar uma palestra no Colégio de Sion no Rio de Janeiro, quando foi recepcionada por Stella de Faro. Adèle Lhoneaux foi seguramente uma referência para Stella de Faro, sendo professora na Escola Social Católica de Bruxelas e uma colaboradora ativa da revista La Femme Belge, publicação de divulgação da ação social feminina e católica citada em alguns textos de Stella de Faro.

É importante lembrar que no entreguerras o Serviço Social começava a se definir como um campo do conhecimento e de prática de ação social em diferentes países. Neste artigo destacamos suas origens católicas francesas e belgas por terem as escolas sociais naqueles dois países exercido notável influência na escola de Serviço Social de São Paulo, criada em 1936, em decorrência do curso ministrado por Lhoneux, e o Instituto Social do Rio de Janeiro, criado em 1937, também em decorrência da organização da ação social e da Ação Católica Brasileira recém-criada em $1935 .^{5}$

Conforme explicou Alceu Amoroso Lima (1938), a Ação Católica tinha dois braços temporais: a ação política e a ação social. Esta, por sua vez, tinha muitos desdobramentos, mas do ponto de vista prático e moral o remédio para os males do mundo moderno estava na organização do conhecimento e das práticas de intervenção fornecidos pelo Serviço Social.

Um dos livros referenciais no mundo francófono sobre o Serviço Social, Le service social a travers le monde (1931), de autoria do médico belga René Sand (1877-1953), apresenta a história do Serviço Social e sua evolução da caridade e da filantropia nos mais diferentes países. Segundo Sand, esta evolução era prova de que as pessoas mais preparadas para atuar na ação social orientada pelos princípios teóricos, técnicos e morais do Serviço Social seriam as mulheres, descritas pelo autor como agentes da

\footnotetext{
${ }^{5}$ A Escola de Serviço Social de São Paulo surgiu do Centro de Estudos e Ação Social de São Paulo, o Ceas, cujos princípios se baseavam na doutrina social da Igreja. A primeira presidente do CEAS foi Odila Cintra Ferreira, que havia estudado na Escola Superior de Estudos Sociais do Instituto Católico de Paris (LIMA, 1983).
} 


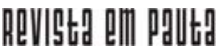

\} AS MULHERES CATÓLICAS E AS ORIGENS - MARTINS, A. P. V. \}

DOI: $10.12957 /$ rep.2021.56088

benevolência que acrescentariam a esta qualidade moral a qualificação profissional. Assim, entende-se por que o Serviço Social se organizou como uma especialização a partir da experiência das escolas sociais católicas, afinal os doutrinadores e estudiosos do catolicismo social perceberam que não bastavam a caridade e a benevolência para enfrentar a questão social. Os problemas se mostravam complexos e requeriam conhecimento, método e técnica a fim de se proporem soluções. Não foi, portanto, coincidência que as escolas sociais, de educação familiar e doméstica criadas desde o fim do século XIX passaram a ser escolas de Serviço Social a partir da década de 1920 e modelos para as escolas católicas criadas no Brasil na década de 1930.

Stella de Faro voltou da França em 1934 e logo em seguida começou a colocar em prática seu plano de criar uma escola católica de educação familiar e de Serviço Social inspirada no Instituto francês dirigido pelas Filhas do Coração de Maria. Este plano articulava a criação da escola e a vinda de religiosas para estabelecer a congregação no Brasil, portanto se tratava de um plano formado por um tripé composto pela expansão da congregação, a ação social e a educação feminina.

Nota-se este movimento nas cartas trocadas entre Dom Sebastião Leme e a superiora geral da Sociedade das Filhas do Coração de Maria, Marie Rascol, que se encontram no acervo do Instituto Social de Curitiba. Dom Leme manifestava em carta de 10 de junho de 1936 sua satisfação em receber a congregação no Brasil, embora a Arquidiocese não pudesse ajudá-las materialmente. Ele afirma sua admiração pelas atividades apostólicas da congregação (ação social e vida consagrada) e sua convicção de que não faltariam vocações no Brasil para a congregação. Em resposta datada de 2 de julho de 1936 Marie Rascol manifesta sua concordância com a instalação da congregação no Brasil e menciona a "primeira pedra" Stella de Faro, com quem se correspondia para acertar os detalhes da viagem das irmãs, as condições de chegada e de instalação, esperando contar com a generosidade e a caridade dos brasileiros.

No ano seguinte, em 1937, chegaram ao Brasil três Filhas do Coração de Maria: Fanny du Rostu, que foi a diretora do noviciado de Stella de Faro em Paris e a primeira superiora da congregação no Brasil até 1946, Germaine Marsaud e a italiana Giacintha Pietromarchi. Assim, com Stella estava formado o núcleo inicial da congregação no Brasil. Em publicação no acervo do Instituto Social de Curitiba há a informação de que imediatamente as religiosas começaram a participar da Ação Católica, da ação social e da educação de jovens mulheres, especialmente no Instituto Social criado no mesmo ano pela intensa mobilização e dedicação de Stella de Faro, que conseguiu apoio entre seus contatos do meio intelectual e militante católico (LA SOCIETE , [1899-1905], p. 181).

Este apoio foi manifesto com a imediata criação da Associação Mantenedora do Instituto Social, cujos nomes demonstram o com- 
prometimento da elite católica do Rio de Janeiro com a criação de uma escola social católica. Faziam parte da diretoria da Associação a filantropa Celina Guinle de Paula Machado, casada com o rico empresário Lineu de Paula Machado; alguns anos mais tarde ela doou o vasto terreno na Rua Humaitá, número 170, no qual foi construída a sede definitiva do Instituto, inaugurada em 1947; o professor e intelectual católico, líder da Ação Católica Brasileira, Alceu Amoroso Lima; o advogado e empresário João Daudt de Oliveira; o empresário e rotariano João Augusto de Mattos Pimenta; Brasilita de Souza e Silva e Firmina Moreira da Fonseca, que faziam parte da Ação Católica; as Filhas do Coração de Maria Stella de Faro e Germaine Marsaud, e mais nove conselheiros, todos católicos, sendo 6 mulheres e 3 homens. Foi uma diretoria majoritariamente feminina, com mais de $60 \%$ de mulheres. Importante destacar que desta diretoria integraram o corpo docente Alceu Amoroso Lima e Germaine Marsaud, mas, na publicação comemorativa dos 10 anos do Instituto, além destes dois nomes, aparecem nomes de vários professores e professoras, laicos e religiosos, todos com experiência profissional em suas respectivas áreas, sendo, portanto, uma escola social com um corpo docente de qualidade, experiente e que atuava em outras instituições.

Stella foi da diretoria do Instituto, ao qual se dedicou integralmente a partir de 1948, quando pediu exoneração do Conselho Nacional de Serviço Social, como representante da Ação Católica Brasileira desde a criação do CNSS em 1938, indicada por Dom Sebastião Leme e Alceu Amoroso Lima. Ela e Germaine Marsaud passaram a ser as "duas pedras" da congregação no Instituto, sendo Germaine diretora técnica e professora de Educação Familiar e de Moral Profissional. Na publicação acima citada da congregação há uma passagem que demonstra a capacidade de articulação das religiosas, com destaque para Germaine Marsaud:

Germaine era uma mulher de notável tenacidade em seus empreendimentos e de um zelo apostólico extraordinário, muito apreciada por todos no Rio de Janeiro. Foi a época quando começaram a surgir os grandes institutos de seguridade social e todos procuravam 'Mademoiselle'para aproveitar de sua experiência. Ela recebeu bolsas de estudos para suas estudantes e ministrou cursos de curta duração para melhor preparar as trabalhadoras sociais. (LA SOCIETÉ, [18991905], p. 281).

É importante ressaltar que a expansão do Instituto para outros estados foi concomitante à expansão da congregação, ampliando-se o número de religiosas brasileiras por meio da Ação Católica e da realização dos retiros religiosos. Assim, é interessante notar que, entre 1940 e 1945, portanto em menos de uma década, já havia Institutos no Recife, em Curitiba, Porto Alegre e Natal, mas também cursos extraordinários foram realizados em acordo com a Legião Brasileira de Assistência (LBA), entre 1942 e 1946, 


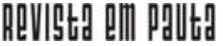

\} AS MULHERES CATÓLICAS E AS ORIGENS - MARTINS, A. P. V. \}

DOI: $10.12957 /$ rep.2021.56088

nessas cidades e em Juiz de Fora, Nova Friburgo, Vitória, Goiânia e Belo Horizonte. Não foi possível localizar o número de estudantes dessas escolas e/ou desses cursos que abraçaram a vida religiosa entrando para a congregação, mas somente no processo de organização do Instituto Social de Curitiba quatro mulheres entraram para a Sociedade das Filhas do Coração de Maria: Irene Teixeira de Freitas, pioneira do Serviço Social no Paraná, Stella Guérios, Nídia Moreira Garcez e Aracy Cardoso (INSTITUTO SOCIAL DE CURITIBA, s.d., p. 7-8) Essa capacidade de atração para a vida religiosa pode ter sido bem sucedida também em outros estados, mas é necessário investigar com mais detalhamento no acervo da congregação no Brasil para conhecer como se deu a relação entre a opção pela vida religiosa e a profissionalização das primeiras assistentes sociais e educadoras familiares formadas pelos Institutos católicos. Sobre essa questão é importante lembrar que as religiosas de outras congregações tiveram formação profissional nas escolas de Enfermagem e de Serviço Social, duas profissões femininas em suas origens e bastante influenciadas pela moralidade cristã ${ }^{6}$ (GOMES et al., 2005; BROTTO, 2014).

Os trabalhos e publicações que existem sobre o Instituto Social do Rio de Janeiro reconhecem a contribuição e a participação de Dom Sebastião Leme, Alceu Amoroso Lima e, num lugar menos visível e secundário, de Stella de Faro. Entretanto, a descoberta de documentos sobre a biografia de Stella e de sua trajetória como militante católica desde a primeira década do século XX demonstra que seu lugar não foi secundário e nem às margens do catolicismo e das origens do Serviço Social, embora não tenha exercido a profissão de assistente social. Como tantas outras mulheres que participaram ativamente do movimento restaurador católico em diferentes países, ela e suas companheiras de vida consagrada defenderam a educação feminina profissional voltada para atender o que então se chamava de problemas sociais, resultantes das profundas transformações econômicas, sociais e culturais desde meados do século XIX e que afetavam as cidades e o campo, com impacto maior na organização da vida familiar e comunitária.

O catolicismo social foi o conjunto de estudos e de organizações religiosas e laicas com o objetivo de restaurar a ordem social pela difusão da moral e dos valores cristãos. Deste amplo e vigoroso movimento, as mulheres participaram ativamente, tanto das organizações devocionais, tão valorizadas pelo catolicismo ultramontano, quanto das organizações assistenciais e educativas, fundamentais para a difusão das ideias do pensamento social católico. A ação social católica contou, portanto, com o trabalho e a organização das mulheres, entre elas as religiosas da Sociedade das Filhas do Coração de Maria, cuja participação e capacidade de mobilização foram fundamentais para a organização feminina católica internacional e que ainda requer estudos mais específicos.

${ }^{6}$ Não há pesquisa histórica alguma sobre a Sociedade das Filhas do Coração de Maria no Brasil. 


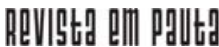

\} AS MULHERES CATÓLICAS E AS ORIGENS - MARTINS, A. P. V. \}

DOI: $10.12957 /$ rep. 2021.56088

Stella de Faro foi uma dessas mulheres. Seu envolvimento com a ação social e a Ação Católica Brasileira se deu como líder e foi a partir de seu conhecimento e contato com outras lideranças femininas internacionais e com o pensamento católico que Stella foi capaz de mobilizar apoios importantes na elite carioca e no clero para uma de suas causas que mais estavam em sintonia com a ação social: a educação social e a profissionalização feminina. Foi, portanto, a partir de seus mais sólidos e intocados valores conservadores que mulheres como Stella de Faro, Germaine Marsaud, Fanny du Rostu, Christinne de Hemptinne e tantas outras Filhas do Coração de Maria contribuíram para a formação de centenas de jovens mulheres que foram as primeiras assistentes sociais e educadoras familiares no Brasil. Independentemente da orientação doutrinária católica que limitava o lugar das mulheres às bem marcadas fronteiras da família e da domesticidade, suas próprias biografias e o projeto educativo e profissional que abraçaram dão mostras de como o conservadorismo forneceu um quadro de referências morais e intelectuais a partir do qual aquelas fronteiras foram ultrapassadas, mesmo que no plano discursivo permanecessem intocadas, assim como as hierarquias de gênero.

A história da profissão do Serviço Social se relaciona profundamente com as concepções conservadoras do gênero e das hierarquias de classe, representadas pela tradicional vinculação das mulheres de elite com as práticas e as organizações de caridade e filantropia. No entanto, a história desta profissão também tem profundas vinculações com a religião cristã que neste artigo foi delimitada pelo catolicismo militante do século XIX e inícios do XX - e o ativismo feminino católico, facetas menos conhecidas das origens do Serviço Social. A história do Instituto Social do Rio de Janeiro é uma oportunidade para começar a reconhecer não só as relações entre esta profissão, a religião e a agência das mulheres católicas, mas também das margens de ação propiciadas pelo conservadorismo. 


\section{Referências}

BACKX, S.de S. Trabalho, família e sociabilidade dos trabalhadores urbanos: reexaminando a história do Serviço Social. Dissertação (Mestrado em Serviço Social) - Programa de Pós-Graduação em Serviço Social, Universidade Federal do Rio de Janeiro, Rio de Janeiro, 1993.

BROTTO, R.B. O sentido de servir: assistência e formação profissional de enfermeiras católicas no Brasil (1931-1961). Tese (Doutorado em História das Ciências) - Programa de Pós-Graduação em História das Ciências e da Saúde, Casa de Oswaldo Cruz-Fiocruz, Rio de Janeiro, 2014.

BROWN, P. Corpo e sociedade. O homem, a mulher e a renúncia sexual no início do Cristianismo. Rio de Janeiro: Jorge Zahar Editor, 1990.

CLARK, E. Catholics and the campaign for women's suffrage in England. Church History, Vol. 73, No. 3 (Sep., 2004), pp. 635-665 Disponível em: http://www.jstor.org/stable/4146569. Acesso em 15 dez. 2014.

COVA, A. Au service de I'Eglise, de la patrie et de la famille. Femmes catholiques et maternité sous la Ille République. Paris: L'Harmattan, 2000.

COVA, A.; DUMONS, B. Destins de femmes. Religion, culture et société, France, XIXe-XXe siècles. Paris: Letouzey et Ané, 2010.

DAWES, $\mathrm{H}$. The catholic church and the woman question: catholic feminism in Italy in early 1900's. The Catholic Historical Review,v. 97, n.3, 2011. Disponível em: www.jstor.org/stable/23052568. Acesso em:5 fev. 2020.

DELLA SUDDA, M. Une activité politique conservatrice avant le droit de suffrage en France et en Italie. Socio histoire de la politisation de femmes catholiques au sein de la Ligue Patriotique des Françaises (1902-1933) et de I'Unione fra le donne cattoliche d'Italia (1909-1919). Tese (Doutorado em Ciências Sociais) - École des Hautes Études em Science Sociales, Universidade de Roma "La Sapienza", 2007.

DROULERS, P. Politique social et christianisme. Le Père Desbuquois et I'Action Populaire. T. II. Dans lagestation d'um monde nouveau (1914-1946). Paris: Éditions Ouvrières, 1981.

ESTATUTO das Filhas do Coração de Maria. Paris: PoussielgueRusand,1828. Disponível em: www.gallica.bnf.fr. Acesso em: 15 de outubro de 2018.

FARO, S. Escolas populares de economia doméstica. Jornal do Brasil, 3 ago. 1908.

FAYET-SCRIBE, S. Associations féminines et catholicisme. De la charité à l'action sociale. XIXe-XXe. siécle. Paris: Les Éditions Ouvrière, 1990. 


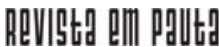

\} AS MULHERES CATÓLICAS E AS ORIGENS - MARTINS, A. P. V. \}

DOI: $10.12957 /$ rep.2021.56088

FOUILLOUX, É. Femmes et catholicisme dans la France contemporaine. Aperçu historiographique. Clio, Femmes, Genre, Histoire, v. 2, 1995. Disponível em: http://clio.revues.org/498. Acesso em: 15 nov.2015.

GIORGIO, M.de. O modelo católico. In: FRAISSE, G.; PERROT, M. (Org.). História das mulheres. O século XIX. Porto/São Paulo: Edições Afrontamento/ Ebradil, 1994.

GOMES, T.de O.et al.Enfermeiras católicas em busca de melhores posições no campo da educação e da prática em enfermagem nos anos 40 e 50 no Brasil, no século XX.Texto \& Contexto,v. 14, n. 4, out./dez.2005.

GUBIN, E. Femmes rurales em Belgique. Aspects sociaux et discours idéologiques XIXe. - XXe. siècles. Clio, Femme, genre, histoire, v. 16, 2002.

GUBIN, E. et al. Dictionnaire des femmes belges. XIXe et XX ${ }^{e}$ siècles. Bruxelles: Éditions Racine, 2006.

INSTITUTO SOCIAL DE CURITIBA. Documento histórico. Curitiba, s.d.

KANE, P.M. The willing captive of home? The english catholic women's league, 1906-1920. Church History, v. 60, n.3, set. 1991.

LA SOCIETÉ des filles du Couer de Marie. Tome Septime, [1899-1905].

LANFREY, A. Les catholiques et l'ecole. 1902-1914. Tese (Doutorado em Letras e Ciências Humanas) - Université Lumiere, Lyon, 1987.

LIMA, A.A. Elementos de ação católica. Rio de Janeiro: Editora ABC, 1938.

LIMA, A.A. Serviço Social no Brasil. A ideologia de uma década. São Paulo: Cortez, 1983.

MACHADO, G. S. Serviço Social, formação brasileira e questão social: na cadência do pioneirismo carioca. Tese (Doutorado em Serviço Social) Programa de Pós-Graduação em Serviço Social, Universidade Federal do Rio de Janeiro, Rio de Janeiro, 2015.

MAHMOOD, S. Politics of piety. The islamical revival and the feminist subject. Princeton/Oxford: Princeton University Press, 2005.

MARTINS, A.P.V. Bondade, substantivo feminino: esboço para uma história da benevolência e da feminilização da bondade. Revista História: Questões \& Debates, n. 59, jul./dez. 2013.

MARTINS, A.P.V. Disciplina e piedade: o movimento feminino católico brasileiro no começo do século XX.Revista Brasileira de História das Religiões, ANPUH, ano X, n. 26, set./dez. 2016.

MESQUIDA, P. A educação na restauração lemista da Igreja: a missão de Tristão de Athayde e Stella de Faro no Ministério da Educação e Saúde Pública. 1934-1945. Revista Diálogo Educacional, v. 9, n. 27, maio/ago. 2009. 


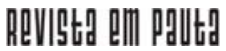

\} AS MULHERES CATÓLICAS E AS ORIGENS - MARTINS, A. P. V. \}

DOI: $10.12957 /$ rep.2021.56088

MESTRINER, M.L. O Estado entre a filantropia e a assistência social. São Paulo: Cortez, 2005.

MEUWLY-GALLEY, C. Suzanne de Montenach (1967-1957). Freiburger Geschichtsblättem. 75, 1998. Disponível em:http://retro.seals.ch. Acesso em: 20 mar. 2018.

PIERRARD, P. Les laḯcs dans la l'Église de France. XIXe-XXe. siècle. Paris: Les Éditions Ouvrières, 1988.

RANKE-HEINEMANN, U. Eunucos pelo reino de Deus. Mulheres, sexualidade e a Igreja Católica. Rio de Janeiro: Editora Rosa dos Tempos, 1996. ROLL, S. Ni bas-bleu, ni pot-au-feu: la conception de "la" femme selon Auguste Moll-Weiss (France, tournant des XIX $-X^{\mathrm{X}} \mathrm{X}^{\mathrm{e}}$ siècles). Genre \& Histoire, n. 5, 2009.

SAND, R. Le Service Social a travers le monde. Assistance, prévoyance, hygiène. Paris: Librairie Armand Colin, 1931.

SARTI, O. The ligue patriotique des françaises. 1902-1933. A feminine response to the secularization of French society. Bloomington: Indiana University Press, 1984.

TURMANN, M. Le développement du catholicisme social. Paris: Félix Alcan Éditeur, 1900.

TURMANN, M. Initiatives féminines. Paris: Librairie Victor Lecoffre, 1905.

WALKOWITZ, D.J. The making of a feminine professional identity: social workers in the 1920's. The American Historical Review, v. 95, n.4, out. 1990. Disponível em: http://www.jstor.org/stable/2163478.Acesso em: 29 jun. 2011.

ZELIS, G. La formation au travail social entre "maternalisme" et professionalisation. Tese (Doutorado em Serviço Social) - L'Ecole Catholique Féminine de Bruxelles, Louvain-la-Neuve, 2001.

DOI: $10.12957 /$ rep.2021.56088

Recebido em 09 de março de 2020.

Aprovado para publicação em 20 de março de 2020.

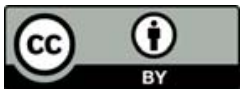

A Revista Em Pauta: Teoria Social e Realidade Contemporânea está licenciada com uma Licença Creative Commons Atribuição 4.0 Internacional. 